\title{
Effects of Vineyard Inter-Row Management on Soils, Roots and Shallow Landslides Probability in the Apennines, Lombardy, Italy ${ }^{\dagger}$
}

\author{
Claudia Meisina 1,*, Massimiliano Bordoni ${ }^{1}$, Alberto Vercesi ${ }^{2}$, Michael Maerker ${ }^{1}$, Cristina \\ Ganimede ${ }^{2}$, Maria Cristina Reguzzi ${ }^{2}$, Enrica Capelli ${ }^{1}$, Emanuele Mazzoni ${ }^{3}$, Sauro Simoni ${ }^{3}$ and \\ Elena Gagnarli 3
}

1 Department of Earth and Environmental Sciences, University of Pavia, Via Ferrata, 1, 27100 Pavia, Italy; massimiliano.bordoni@unipv.it (M.B.); michael.maerker@unipv.it (M.M.); enrica.capelli@unipv.it (E.C.)

2 Department of Sustainable Crop Production, Università Cattolica del Sacro Cuore, Via Emilia Parmense, 84, 29122 Piacenza, Italy; alberto.vercesi@unicatt.it (A.V.); cristina.ganimede@unicatt.it (C.G.); cristina.reguzzi@gmail.com (M.C.R.)

3 Research centre for Plant Protection and Certification, CREA, Via Lanciola, 12A, 50125 Florence, Italy; emanuele.mazzoni@unicatt.it (E.M.); sauro.simoni@crea.gov.it (S.S.); elena.gagnarli@crea.gov.it (E.G.)

* Correspondence: claudia.meisina@unipv.it

† Presented at TERRAenVISION 2019, Barcelona, Spain, 2-7 September 2019.

Published: 25 December 2019

\begin{abstract}
Cultivation of grapevines in sloping soils is very widespread all over the world, representing also a fundamental branch of the local economy of several hilly zones. Vineyards can be managed in different ways especially the inter-rows. These management practices may influence deeply soil properties and grapevine root development. Therefore, this work aims to analyze the effects of different agronomical practices of inter-rows on soil properties, grapevine root systems and proneness towards shallow landslides. We focused on traditional agricultural techniques of tillage and permanent grass cover as well as the alternation of these two practices between adjacent inter-rows. The studied parameters were: (i) soil physical and hydrological properties; (ii) soil biodiversity; (iii) root density; (iv) root mechanical properties and root reinforcement; (v) probability of occurrence of shallow landslides. The research was conducted in several test-sites of the Oltrepò Pavese (Lombardy region, north-western Italy), one of the most important Italian zones for wine production in northern Italian Apennines. Among the examined soil properties, soil hydraulic conductivity was the most influenced one by different soil management practices. The absence of soil tillage allowed to increase superficial (first $0.2 \mathrm{~m}$ of soil) hydraulic conductivity, as a consequence of higher macroporosity and amount in organic matter. Within the soil biological features, soil microarthropod communities showed more complexity where permanent grass cover or alternation management of the inter-rows were applied. Regarding the features of the grapevine root system, vineyards with alternation management of inter-rows had the highest root density and the strongest root reinforcement, of up to $45 \%$ in comparison to permanent grass cover, and up to $67-73 \%$ in comparison to tilled vineyards. As a consequence, slopes with medium steepness $\left(10-18^{\circ}\right)$ were unstable if inter-rows of vineyards were tilled, while vineyards with permanent grass cover or alternation in the inter rows promoted the stability of slopes with higher steepness $\left(>21-25^{\circ}\right.$ for vineyards with permanent grass cover in the inter rows, $28-33^{\circ}$ for vineyards with alternation). The results of this study yielded important information to establish effective management practices of vineyards such as conserving organic matter and reducing slope instabilities by a better development of the root apparatus. Possible land use managements acting as mitigation measures for shallow landslides susceptibility could be also implemented. This work was supported by the project Oltrepò BioDiverso, funded by Fondazione Cariplo in the frame of AttivAree Program.
\end{abstract}


Keywords: vineyard; soil; root; shallow landslides; land management

(C) 2019 by the authors. Licensee MDPI, Basel, Switzerland. This article is an open access article distributed under the terms and conditions of the Creative Commons Attribution (CC BY) license (http://creativecommons.org/licenses/by/4.0/). 